\title{
OFERTA DE EMPREGO: HABILIDADES NECESSÁRIAS PARA ARQUIVISTAS EM EMPRESAS NO BRASIL
}

\section{OFFER OF EMPLOYMENT: SKILLS REQUIRED FOR ARCHIVISTS IN COMPANIES AT THE BRAZIL}

\author{
Eliana Maria dos Santos Bahia Jacinthoa \\ José Antonio Moreiro Gonzalez ${ }^{b}$
}

\begin{abstract}
RESUMO
Introdução: o presente estudo analisa as habilidades requeridas aos arquivistas e documentalistas brasileiros em ofertas de emprego disponíveis para gestão da informação em empresas, indústrias e organizações. Objetivo: mapear as habilidades requeridas aos arquivistas no mercado de trabalho brasileiro. A mineração dos termos, no período 2012-2014, em anúncios disponíveis no Portal Catho (www.catho.com.br). Utilizou-se a estrutura taxonômica no TEMATRES - software para gestão de tesauros. Metodologia: aplicou neste estudo o método exploratório qualitativo e quantitativo. Resultados: os dados mostram uma incidência relevante das habilidades, com solicitação média de três habilidades específicas em cada um dos 3.291 anúncios analisados, que são: aptidões instrumentais, habilidades computacionais e habilidades pessoais. Conclusões: o mercado de trabalho estudado requere como perfil profissional habilidades específicas aos candidatos arquivistas e documentalistas, tais habilidades são decisivas para a seleção desses profissionais. As habilidades identificadas revelam um novo contexto laboral e social, no qual, arquivistas e documentalistas desenvolvem as suas funções de acordo com a qualificação exigida pelo mercado.
\end{abstract}

Descritores: Arquivistas empresariais. Habilidades - Arquivista. Ofertas de emprego. Portal Catho - Brasil. Mercado de trabalho. Taxonomia. TEMATRES.

\section{INTRODUÇÃO}

Os dirigentes precisam controlar a informação para gerir suas empresas e instituições, para a tomada de decisões e, ainda, para a melhoria interna no

a Doutora em Documentación: Archivos na Universidad Carlos III de Madrid- Espanha. Professora do Departamento de Ciência da Informação da Universidade Federal de Santa Catarina (UFSC). E-mail: elianambahia@gmail.com

b Doutorado pela Universidad Nacional de Educación à Distancia (UNED). Atualmente, Catedrático da Universidad Carlos III de Madrid. E-mail: jamore@bib.uc3m.es 
fluxo das informações. Para tanto, os arquivos desempenham um papel estratégico como elementos centrais da estrutura organizacional para a organização, controle, e, o acesso à informação. Os arquivistas, assim como os documentalistas, precisam transformar informação e conhecimento em matériaprima de valor agregado para as organizações (empresas e instituições), de modo a colocá-las um passo à frente de seus concorrentes. Abre-se, assim, uma nova perspectiva em relação à Arquivologia pós-custodial, quando os documentos têm evoluído a partir de objetos físicos a objetos virtuais (FONSECA, 2005, p. 63). A situação requer dos arquivistas uma resposta técnica e objetiva, em uma sociedade com profissionais competentes e qualificados, não apenas na Ciência da Informação, mas em todo o setor produtivo (VALENTIM, 2008).

As universidades, de maneira geral, também precisam conhecer com exatidão os perfis profissionais procurados pelas empresas e instituições empregadoras, para ajustar os currículos, no sentido de alcançar as competências e habilidades exigidas pelo mercado. Dessa forma, o arquivista tem condições de agir, de maneira eficaz e competente, no cenário de trabalho.

Preferimos, aqui, falar de habilidades, e do seu sinônimo aptidões, como disposições naturais ou adquiridas para melhor distinguir os comportamentos adequados das competências, entendidas como o conjunto das capacidades necessárias ao exercício profissional da Arquivologia. As habilidades são, então, competências de caráter genérico decisivas no perfil de um bom profissional. Mais do que as competências cognitivas, o domínio de habilidades origina a eficácia de um arquivista, da mesma forma que causa a sua correta inserção no âmbito profissional.

Propomo-nos a deduzir como o arquivista brasileiro deve desempenhar seu trabalho, a partir das expectativas do setor empresarial. Isso supõe, em primeiro lugar, a análise de anúncios de emprego para identificação das habilidades e competências requeridas dos arquivistas pelo mercado de trabalho, no setor privado. E, além disso, desenvolver uma taxonomia hierárquica para ordenar tais habilidades, a fim de obter o perfil profissional adequado à atuação no mercado corporativo (BAHIA, 2016). 
Parte-se de dois pressupostos: 1) existe um papel definido para os arquivos nas empresas, indústrias e organizações no contexto da gestão da informação e isso requer competências e habilidades concretas dos profissionais arquivistas; e 2) a gestão da informação produzidas nas/pelas empresas, indústrias e organizações facilitam seu compartilhamento e seu desenvolvimento futuro.

Assumimos, dessa forma, que os arquivistas e documentalistas integrados nas planilhas das empresas e instituições estão requeridos por elas para melhorar a sua qualificação de habilidades e atitudes, já que sobre tal melhoria se alça seu diferencial competitivo.

Como objetivo geral, propõe-se verificar as habilidades e as competências exigidas dos arquivistas pelo mercado de trabalho, a partir das ofertas apresentadas nos anúncios feitos pelas empresas.

Quanto aos objetivos específicos, busca-se: a) identificar os conceitos expressos nos anúncios referentes às ofertas de emprego para arquivistas disponíveis no Portal Catho (www.catho.com.br); b) verificar as demandas do mercado de trabalho para os arquivistas e suas exigências; e c) organizar os termos e conceitos obtidos, utilizando uma taxonomia terminológica.

Nos países com maior tradição universitária na Ciência da Informação é um hábito analisar a relação entre os cursos universitários e as circunstâncias do mercado de trabalho. Geralmente, essa exploração é realizada a partir de medições fiáveis, efetuadas com técnicas estatísticas sobre as quais, em seguida, deduz-se a análise qualitativa. A informação é, usualmente, obtida através da utilização de métodos analíticos provenientes das ciências sociais, principalmente por meio da aplicação de questionários, entrevistas ou análise de conteúdo.

O interesse em examinar as condições e exigências do mercado de trabalho coincide com aquele de entender se os currículos estão adaptados às demandas desse mercado e, também, para fomentar, nas empresas e instituições profissionais, a compreensão acerca das necessidades de atualização.

Cada vez atende-se mais aos anúncios de emprego quando se estuda o 
mercado de trabalho. Certamente, porque oferecem a vantagem de um corpo de extração de informações mais objetivo, como expressão direta das necessidades dos contratantes; não dependem de recebimento de respostas necessárias para questionários e/ou entrevistas; e, ainda, possibilitam o estudo imparcial das exigências do mercado de trabalho. Garante-se, sempre, a dedução posterior, utilizando ferramentas de análise de conteúdo e critérios estatísticos.

\section{METODOLOGIA}

A utilização de anúncios de emprego no Brasil mostra uma reiterada predileção pelas ofertas disseminadas por meio de páginas web, devido a facilidade de acesso e pela recorrente atualização de suas informações. Emprega-se, especialmente, o Portal Catho (www.catho.com.br) como fonte preferente de mineração. Assim como nos estudos publicados por Cunha (2006), Duarte e Braga (2010), esta abordagem metodológica foi seguida, muito de perto, como nosso procedimento, pelas contribuições de Moreiro Gonzalez e Vergueiro (2012), Moreiro Gonzalez, Vergueiro e Sánchez-Cuadrado (2012) e por Bahia e Moreiro (2014). É, assim, uma fonte comprovada e confiável, capaz de contar com uma metodologia de análise bem definida. A novidade do estudo provê de sua aplicação aos arquivistas do setor privado.

Foram selecionadas as ofertas de emprego divulgadas durante os anos 2012, 2013 e 2014 no Portal Catho (www.catho.com.br), um portal empresarial de anúncios de trabalho. A seleção dessa fonte deu-se a partir do critério de abrangência, todo o território brasileiro, e pela garantia de acesso num portal que atua desde 1977, com ofertas de vagas de emprego de perfil profissional para todas as áreas de atuação. Para assegurar a veracidade dos anúncios divulgados, o Portal Catho verifica os dados cadastrais das empresas anunciantes e o conteúdo das vagas ofertadas.

Como método para a busca de trabalho, o Portal Catho combina as vantagens de anúncios de ofertas que se mostram em portais de empregos pertencentes a webs corporativas, o que representa as condições utilizadas pelos graduados quando procuram emprego. A mostra foi obtida através da 
identificação dos anúncios cujo título contivesse as palavras "arquivo" ou "arquivista", mesmo em sintagmas compostos como "técnico em arquivo" ou "assistente arquivista", e que expressarem, claramente, as tarefas, habilidades e competências exigidas do candidato à vaga. Registrou-se um total de 5.295 anúncios de ofertas de emprego, dos quais 3.291 anúncios foram válidos e 2.004 foram anúncios repetidos.

O processo de análise começou pela identificação e extração manual dos conhecimentos que eram solicitados nos anúncios. Extrair o corpus terminológico dos documentos analisados e um processo comprovado por Larose (2006). Cada uma das expressões obtidas foi relacionada com todos os seus sinônimos, em face de sua utilização expressiva para um conteúdo dado. Sempre que uma expressão se repetia em alguma das ofertas analisadas, a ocorrência era acrescentada em seu contador, para conhecer a importância do conceito representado no contexto geral. Revisou-se, ainda, a normalização das formas de entrada nos campos de descrição, segundo a norma ISO 25.964 (2011).

Para gerar as classes da taxonomia e integrar nelas os termos, utilizouse o método dedutivo (JAGERMAN, 2006). Para isso, foi necessário elaborar uma estrutura de classificação, à qual foram relacionados os conceitos a serem agregados. Cada entrada na taxonomia foi encabeçada por um termo preferente, eleito entre os vários equivalentes possíveis. O software de gestão documental TEMATRES garantiu a construção da taxonomia hierarquizada, uma adequada navegação por sua estrutura, assim como a visualização de todas as categorias introduzidas (GONZALEZ-AGUILAR; RAMÍREZ-POSADA; FERREYRA, 2012).

A identificação e análise das habilidades solicitadas nesses tipos de anúncios na web seguiram as propostas de Cloonan e Norcott (1989), Mendes e Simões (2002) e Harper (2013), que apresentaram o mesmo fim, mas diferentes modos de estudo.

\section{RESULTADOS: CARACTERÍSTICAS DA TAXONOMIA HIERÁRQUICA}

A taxonomia sistematiza os resultados da extração de terminologia e põe 
ordem nos termos, organizando-os em classes hierárquicas. A estrutura da taxonomia hierarquizada contém 18 macroclasses, a saber:

1) Análise e representação da informação;

2) Conservação e restauração de documentos;

3) Contexto legal e administrativo;

4) Corporações e instituições;

5) Fontes de informação;

6) Gestão de documentos;

7) Gestão de projetos e técnicas de planejamento;

8) Habilidades;

9) Interação com produtores, usuários e clientes;

10) Profissão em Arquivologia;

11) Protocolo;

12) Técnicas de arquivo;

13) Técnicas comerciais;

14) Técnicas de instalação de equipamento e adequação;

15) Técnicas de gestão de pessoal;

16) Tecnologia da informação e informática;

17) Transparência na gestão da informação;

18) Unidades de informação.

As 18 macroclasses incluem 3.291 termos preferentes e 475 termos não preferentes. Surgiram 501 relações de equivalência. Em relação ao respeito aos níveis de especificidade de representação de conhecimento, a taxonomia atingiu até os 10 níveis, o que representa, ao mesmo tempo, a profundidade da análise realizada e da alta exigência ao profissional que atinge tarefas de especialização, que chegam a ser muito determinadas.

A representação da taxonomia é hierárquica multinível, sem símbolos de nível, apenas assinaladas em vermelho. É, consequentemente, uma taxonomia de representação plana e exclusivamente terminológica, ainda longe das características semântico-ontológicas, como apresentado no exemplo:

Capacidades de gestão

Capacidade para o trabalho $\leftrightarrow$ Métodos de trabalho do arquivista

$\leftrightarrow$ Técnicas dos profissionais arquivistas (55)

Nível de consciência do ambiente do trabalho (27)

Eficiência $\leftrightarrow$ Profissional arquivista eficiente (23) 


\subsection{HABILIDADES MAIS SOLICITADAS}

A macroclasse número 8 contém as habilidades necessárias para ser selecionado pelas empresas, indústrias e organizações analisadas. Esta parte da taxonomia vem integrada por 87 termos preferentes e 116 sinônimos, os quais, em qualquer das expressões, têm aparecido 10.412 vezes nos 3.291 anúncios identificados. A incidência é muito alta, pois representa uma solicitação média acima de três aptidões por anúncio. Essa cifra dá ideia do valor que as habilidades adquirem nas exigências das corporações. A macroclasse "Habilidades" se dispôs em três classes conceituais:

Aptidões instrumentais, com 9.560 aparições;

Habilidades computacionais, com 310 ;

Habilidades pessoais, com 542 ocorrências.

A desigual ponderação fez com que a determinação da análise se fizesse ao nível de classes mais específicas. De forma geral, nas frequências numéricas mostradas, agrupam-se os termos cabeçalho das subclasses com os seus sinônimos e específicos.

\subsubsection{Aptidões Instrumentais}

O termo genérico cabeçalho da classe "aptidões instrumentais" aparece 76 vezes. Esta categoria contém as classes específicas:

Capacidades de relacionamento (32 termos, 48 sinônimos; 4221 aparições).

Autonomia (1 termo, 0 sinônimos; 18 aparições).

Capacidade de comunicação (14 termos, 24 sinônimos; 1527 aparições). Empatia (32 termos, 48 sinônimos; 724 aparições).

Espírito de equipe (5 termos, 8 sinônimos; 992 aparições).

Aptidão de negociação (5 termos, 4 sinônimos; 960 aparições).

Capacidades de gestão (5 termos, 8 sinônimos; 557 aparições).

Capacidades de organização (15 termos, 20 sinônimos; 1624 aparições).

Capacidade de organização (1 termo, 3 sinônimos; 126 aparições)

Capacidade de adaptação (4 termos, 3 sinônimos; 484 aparições)

Capacidade para tomada de decisões (10 termos, 7 sinônimos; 1014 ap.) 
Sentido de iniciativa e espírito empreendedor (4 termos, 16 sinônimos; 889 ap.).

Capacidade de liderança ( 7 termos, 2 sinônimos; 628 aparições).

Capacidade crítica (7 termos, 9 sinônimos; 757 aparições).

Comportamento ético (6 termos, 5 sinônimos; 990 aparições).

Vamos ponderar a importância das classes intermediárias segundo a sua frequência de aparição. Nota-se que as seis primeiras subclasses mostram presença acima de $25 \%$ nos anúncios analisados. Já a classe "capacidade de comunicação" alcança uma magnitude determinante, incluindo as habilidades de comunicação pessoal, capacidade de transferência de conhecimentos e as competências linguísticas para expressar-se em uma ou mais línguas de comunicação internacional. As habilidades de comunicação têm presença em, praticamente, metade dos anúncios (46,39\%), com 1.527 solicitações, entre as quais as aptidões comunicativas faladas, escritas e audiovisuais são um aspecto chave (709 incidências). Especialmente aplicadas em momentos de negociação e elaboração de relatórios claros e bem estruturados, as habilidades de comunicação são fundamentais para decantar a balança quando encontrar um bom trabalho. Nesta subclasse é avaliado o discurso escrito claro, regulamentado e ordenado, juntamente com a capacidade de falar em público com fluência e apoiar-se nos meios audiovisuais disponíveis.

Mais incomum é que a subclasse dos idiomas só apareça como requisito em menos da quarta parte das ofertas (641 aparições, ou 19,47\%). De maneira geral, tal subclasse manifestou-se 153 vezes como "conhecimento de língua estrangeira". Já de forma específica, foram 488 as menções, com o Inglês como língua mais solicitada, em 171 ofertas, sempre com exigência de níveis avançados de fluência, seguida pelo Espanhol (108 ofertas) e o Francês (95 ofertas), longe de outros idiomas como o Japonês (22), Italiano (20) e Alemão (19). A relevância acentua-se ao considerar que o trabalho vai se desenvolver em equipe internacional (116 vezes), para o qual se deve ter conhecimento de Inglês ou de outro idioma comumente usado em ambientes de negócios.

Ainda em relação às línguas, destaca-se a importância que elas têm quanto à contratação de profissionais. Volta-se a mostrar, como já fizeram 
Duarte e Braga (2010), que o idioma Inglês é requisito genérico, utilizado habitualmente nas empresas do setor. Se acompanhado de outra língua, é determinante e concede grandes vantagens competitivas e salariais. No entanto, o fato de tais habilidades - relacionadas a outras línguas - só receber uma demanda média indica que a maioria das empresas em que trabalham os graduados opera a nível nacional. Isso explica, também, a situação contrária: a exigência do Inglês com outra língua representa $31 \%$ dos casos nas empresas que operam em um cenário internacional.

Com 1.014 ocorrências, ocupando quase dois terços da categoria "capacidades de organização" e presente em, aproximadamente, um terço de todos os anúncios, destaca-se a "capacidade para tomada de decisões". Completam a categoria de aptidões específicas a "capacidade de organização" (126 aparições) e a "capacidade de adaptação", com 484 aparições. Essas são capacidades muito apreciadas na Ciência da Informação, pois organizar sempre foi uma de suas finalidades. Organizar acervos, processos, vocabulários, enfim, por ordem nas coisas oferece a vantagem de sua utilidade e eficácia no exercício da profissão. A importância das aparições relativas à "capacidade para tomada de decisões" é explicável desde o comportamento desejado pelo setor empresarial e institucional. Se completada com "autonomia", ou aptidão para agir independentemente, mostra-se como uma capacidade visível e representativa do desenvolvimento da situação profissional, que permite proceder, no momento oportuno, com coerência em relação aos objetivos procurados e ao conhecimento do contexto de ação.

A aptidão "espírito de equipe" também surgiu em larga escala, ao mostrarse em 30,14\% das ofertas (992 aparições), com seus termos correlatos "integração em equipe" ou "trabalho em equipe". É uma subclasse integrada, apenas, por cinco termos e oito sinônimos. Por sua organização interna e serviço externo, os arquivos são uma extensão das empresas e sociedades as quais servem. Empresas e arquivos desenvolvem sua atividade num ambiente de trabalho baseado na colaboração com outras pessoas (FLEURY; FLEURY, 2004), o que obriga a trabalhar em conjunto para alcançar objetivos comuns, escutar e respeitar opiniões diferentes, ouvir sugestões, aceitar críticas, confiar 
no trabalho do outro e delegar tarefas. Sua relevância coincide com os resultados mostrados em análise semelhante nos Estados Unidos (NIELSEN, 2013) e na Espanha (TEJADA-ARTIGAS; CHACÓN JARÉN; MOREIRO-GONZÁLEZ, 2014).

Tabela 1 - Subclasses com frequência (fi) por acima das 500 aparições

\begin{tabular}{|l|r|l|}
\multicolumn{1}{c|}{ Habilidades } & \multicolumn{1}{l}{ fi } & \% de anúncios \\
\hline Capacidade de comunicação & 1527 & 46,39 \\
\hline Capacidade para tomada de decisões & 1014 & 30,81 \\
\hline Espírito de equipe & 992 & 30,14 \\
\hline Comportamento ético & 990 & 30,08 \\
\hline Aptidão para a negociação & 960 & 29,17 \\
\hline Sentido de iniciativa e espírito empreendedor & 889 & 27,01 \\
\hline Capacidade crítica & 757 & 23,00 \\
\hline Empatia & 724 & 21,99 \\
\hline Capacidade de liderança & 628 & 19,08 \\
\hline Capacidades de gestão & 557 & 16,92 \\
\hline
\end{tabular}

Fonte: elaboração dos autores.

Dados praticamente iguais obteve a presença da subclasse "compromisso ético", com 990 aparições. A referida subclasse inclui os descritores "consentimento", "honestidade", "integridade", "respeito" e "seriedade". A aplicação da ética no trabalho beneficia um maior nível de produção, a criação de um ambiente de trabalho harmonioso, respeitoso e agradável e, ainda, aumenta o índice de confiança entre o empregador e seus colaboradores. Como se fosse pouco, os funcionários trabalham com documentação sigilosa. Para Dworkin (2007, p. 230), esses valores vinculam o comportamento privado e o trabalho público. As normas não são apenas acordos entre os cidadãos para alcançarem uma experiência social pacífica, elas devem representar a moralidade compartilhada entre os membros de uma comunidade, empresa, indústria ou organização.

A "aptidão para a negociação" segue como uma significação de 960 aparições, próximo de $30 \%$ dos anúncios, que exigem um bom relacionamento individual e coletivo em representação da empresa ou instituição. É uma capacidade derivada da atuação em um contexto corporativo, sempre de acordo com os interesses da empresa. Supõe aplicar estratégias adequadas, evitando 
o confronto e, com isso, contribuindo para que as negociações deixem as partes satisfeitas. Relaciona-se, ainda, com a capacidade de identificar necessidades, saber argumentar e dar resposta às objeções.

A necessária cultura empresarial e a visão clara dos eventos e dos intercâmbios no contexto socioeconômico mostram-se pela demanda de "sentido de iniciativa e espírito empreendedor", cuja progênie chega a completar 889 aparições. Sua elevada presença já foi discutida por Bahia e Moreiro (2014). O referido grupo completa-se com a demanda de criatividade, adaptabilidade e aproveitamento das oportunidades, especialmente na adaptação à mudança empresarial (484 incidências), para modificar as funções e tarefas desenvolvidas, sempre que necessário. Adquire, assim, relevância saber atuar como arquivista dentro das empresas e instituições, em coerência com seus objetivos e missões.

Completa-se com a "capacidade crítica e analítica" (757 aparições) para saber confrontar as próprias crenças, os planos e objetivos, sendo capaz de mudar de ideia, depois de avaliar todas as possibilidades, de forma racional e objetiva (GUIMARÃES, 2012, p. 108). Finalmente, das 10 subclasses que tiveram uma frequência acima de 500 aparições, discutem-se as três últimas subclasses. A "empatia", subclasse que se materializou 724 vezes, ressalta a percepção dos outros, seus pedidos, argumentos e pontos de vista. É necessária para o trabalho em equipe, para a gestão, organização e para o senso ético, mas é, especialmente, relevante para a compreensão do outro e do reconhecimento da diversidade humana e do multiculturalismo (365). Mostra, assim, especial sensibilidade com a compreensão de diferentes ideologias, culturas e conceitos como identificação do outro e da variedade de modelos sociais. Entender a diversidade cultural, religiosa e de costumes enriquece a pessoa e dá uma visão mais realista do mundo.

Em seguida, surge a "capacidade de liderança", manifestada 628 vezes. Tal habilidade influencia os membros da equipe a cumprir as metas e necessidades da empresa. Por fim, a "capacidade de gestão", conformada pelos termos específicos "capacidade para o trabalho" (82 aparições), "eficiência" (23 aparições), "proatividade" (285 aparições) e "profissionalismo do arquivista" (167 
aparições), serve para assegurar-se da conclusão do trabalho e da qualidade em todos os seus componentes.

\subsection{OUTRAS HABILIDADES}

Os requisitos que demandam as ofertas de trabalho analisadas em relação à computação têm sido diferenciados na taxonomia entre os conhecimentos de caráter habilidoso, respeito à informática, de índole transversal, e as ferramentas, programas e serviços informáticos, atendidos, exclusivamente, na família terminológica 16, "tecnologia da informação e informática". Esta é composta por 206 termos, entre os quais "conhecimento dos sistemas automatizados de informação", "gestão de software documental", "decodificação", "desenvolvimento de aplicações informáticas”, "open acess", "open source", "edição eletrônica", "bases de dados", "aplicação da tecnologia web 2.0", "digitalização e conhecimento de arquivo digital". Também os nomes de software específicos que aparecem nas ofertas feitas nos anúncios.

A classe "habilidades computacionais" é integrada por cinco termos e quatro sinônimos, que apareceram em 310 ocasiões. O caráter dos termos é próprio das aptidões, mais do que relativo aos conhecimentos ou à experiência, como justificam os próprios nomes dos termos: acompanhamento das novas tecnologias, conhecimentos de informáticas, filosofia de licenciamento de software livre. Mantivermos, aqui, essa pequena classe, sem dúvida, devido a sua atual exigência genérica em todos os setores acadêmicos e profissionais. Também porque denota que sua combinação com as competências tecnológicas, antes citadas, é indispensável para realizar, com efetividade, as atividades. Complementam as ferramentas de computação, aportando um comportamento que as concede eficácia de uso. São, dessa forma, disposições naturais ou adquiridas, ao que se refere à expressão "nativos digitais" (PRENSKY, 2001), que garante a possibilidade de sucesso com a tecnologia, a respeito de suas contínuas mudanças. Assegura, assim, um espaço potencial de desenvolvimento ao explicar o comportamento pessoal ante a tecnologia cujas competências são, em nosso caso, identificadas em outra família terminológica, 
a 16.

Por fim, consideramos a classe das "habilidades pessoais", que estrutura tão somente cinco termos preferenciais e três sinônimos, mas que chegam a mostrar-se 542 vezes. Essa classe integra aptidões de importância crescente: capacidade de aprendizagem e autoaprendizagem (157); criatividade e imaginação (193); generosidade (20); e intuição (172). Tais aptidões têm a ver com valores e características pessoais que permitem operar, de forma eficaz, na sociedade. Destaca-se o reconhecimento da importância alcançada pela autoaprendizagem como resposta à necessária aprendizagem ao longo da vida.

\section{CONCLUSÕES}

As habilidades identificadas revelam um novo contexto laboral e social, no qual o arquivista pode desenvolver suas funções. As empresas, indústrias e organizações, impulsionadas pela globalização, estão colaborando para a formação de novos perfis profissionais no mercado de trabalho e, consequentemente, tais perfis precisam ser atendidos na formação oferecida pelas universidades. As mudanças resultantes desse cenário exigem dos profissionais arquivistas aptidões de atuação diferenciadas.

A análise feita das ofertas de emprego permite comprovar que as entidades e instituições empregadoras concedem às habilidades importância fundamental, tornando-as cada vez mais decisivas para a seleção de pessoal. Torna-se necessário, portanto, valorizá-las e desenvolvê-las através dos meios adequados.

As atividades dos processos técnicos comuns às diferentes especialidades das empresas, indústrias e organizações ocuparam grande parte das habilidades mais requisitadas, em especial aquelas relacionadas ao atendimento de clientes e usuários, o que tem bastante lógica, haja vista a missão social a ser desenvolvida pelos profissionais da Ciência da Informação.

As habilidades adquirem-se não apenas nos centros de formação. Embora seu papel seja crucial, o desenvolvimento das habilidades não se limita aos processos de aprendizagem formal. Além disso, não termina quando os 
acadêmicos se inserem no mercado de trabalho. No entanto, na medida em que a contribuição da universidade é maior, mais alto será o padrão exigido pelos formandos que, consequentemente, mais facilmente ganharão o nível exigido pelas vagas disponíveis.

A taxonomia manifestou-se como uma estrutura adequada para organizar o conhecimento extraído do corpus analisado, haja vista que favorece a identificação contextual de cada termo e permite, muito facilmente, conhecer sua importância total e relativa entre todos os termos obtidos.

A transformação digital não é tanto uma transformação tecnológica como uma transformação cultural. Não se refere, apenas, a informatizar a gestão interna ou ter presença institucional na Internet, mas servir aos usuários e dar acesso aos documentos através da rede, junto à necessidade de realizar negócios mediante a web, quando os arquivos servem às corporações. Assim, a formação de profissionais nas universidades, que até o momento tendeu para uma homogeneidade excessiva, deve adaptar-se a uma sociedade que está começando a exigir profissionais diferenciados, capazes de fornecer outra maneira de pensar e, assim, incentivar a inovação e a adequada adaptação às mudanças.

Espírito de equipe, capacidade de comunicação, capacidade para a tomada de decisões, comportamento ético, aptidão para a negociação e empreendedorismo - espírito de iniciativa caracteriza-se como denominadores comuns nas exigências que as ofertas fazem para selecionar candidatos. Assim, contra a crença geral dos alunos, de que o mais importante para conseguir um emprego é o conhecimento específico, são determinantes as habilidades mencionadas.

\section{REFERÊNCIAS}

BAHIA, E. M. dos S.; MOREIRO-GONZÁLEZ, J. A. Archivos y documentalistas empreendedores: el caso español y brasileño. Informação \& Sociedade:

estudos, v. 24, n. 2, p. 121-138, maio/ago. 2014. Disponível em: http://www.ies.ufpb.br/ojs2/index.php/ies/article/view/16539/11538. Acesso em: 13 jan. 2016. 
BAHIA, E. M. dos S. El mercado de trabajo para archiveros según los anuncios brasileños de empleo (2012-2014): análisis y organización terminológicos de ofertas empresariales. 2016. $577 \mathrm{f}$. Tesis (Doctorado en Documentación: Archiveros y bibliotecas en el entorno digital) - Universidad Carlos III de Madrid, Departamento de Biblioteconomía y Documentación, Madrid, 2016. Disponível em: http://www.bu.ufsc.br/teses/ES0052-T.pdf. Acesso em: 04 abr. 2016.

CLOONAN, M. V.; NORCOTT, P. C. Evolution of preservation librarianship as reflected in job descriptions from 1975 through 1987. College \& Research Libraries, v. 50, n. 6, p. 646-656, 1989. Disponível em: http://crl.acrl.org/content/50/6/646.full.pdf. Acesso em: 19 fev. 2016.

CUNHA, M. I. da. Docência na universidade, cultura e avaliação institucional: saberes silenciados em questão. Revista Brasileira de Educação, v. 11, n. 32, p. 258-371, maio/ago. 2006. Disponível em: http://www.scielo.br/pdf/rbedu/v11n32/a05v11n32.pdf. Acesso em: 23 mar. 2016.

DUARTE, E. A.; BRAGA, R. M. de O. O profissional bibliotecário e o domínio da língua inglesa. Encontros Bibli: Revista Eletrônica de Biblioteconomia e Ciência da Informação, v. 15, n. 30, p. 105-122, 2010. Disponível em: http://dx.doi.org/10.5007/1518-2924.2010v15n30p105. Acesso em: 21 mar. 2016.

DWORKIN, R. O império do direito. São Paulo: Martins Fontes, 2007.

FLEURY, A.; FLEURY, M. T. L. Estratégias empresariais e formação de competências: um quebra cabeça caleidoscópio da indústria brasileira. 3. ed. rev. amp. São Paulo: Atlas, 2004.

FONSECA, M. O. K. Arquivologia e Ciência da Informação. Rio de Janeiro: Editora FGV, 2005.

GONZALEZ-AGUILAR, A.; RAMÍREZ-POSADA, M.; FERREYRA, D. Tematres: software para gestionar tesauros. El Profesional de la Información, v. 21, n. 3, p. 319-325, maio/jun., 2012.

GUIMARÃES, G. Liderança positive: para atingir resultados excepcionais. São Paulo: Évora, 2012.

HARPER, R. Knowledge management through the lens of library and information science: a study of job advertisements. Library trends, v. 61, n. 3, p. 703-734, 2013. Disponível em:

http://muse.jhu.edu/journals/library_trends/v061/61.3.harper.html. Acesso em: 13 jan. 2016.

INTERNATIONAL STANDARD ORGANIZATION. ISO 25.964: Thesauri and Interoperability with other vocabularies. Part 1: Thesauri for information 
retrieval. Geneve: International Standard Organization, 2011. Disponível em: http://www.iso.org/iso/iso_catalogue_catalogue_tc/catalogue_detail.htm?csnum ber=7776. Acesso em: 13 jan. 2016.

JAGERMAN, E. Creating, maintaining And Applying Quality Taxonomies. Zoetermeer, 2006. 119 p.

LAROSE, D. T. Data Mining Methods and Models. Hobooken: Wiley-IEEE Press, 2006.

MENDES, M. T. P.; SIMÕES, M. da G. Indexação por assuntos: princípios gerais e normas. Lisboa: Gabinete de estudo a\&b, 2002. Disponível em: https://estudogeral.sib.uc.pt/bitstream/10316/20805/1/Indexacao\%20por\%20as suntos.pdf. Acesso em: 11 nov. 2015.

MOREIRO-GONZALEZ, J. A.; VERGUEIRO, W. de C. S.; SÁNCHEZCUADRADO, S. Análise do contexto de emprego dos profissionais brasileiros da Informação-Documentação a partir de ofertas de trabalho na Web feitas por empresas e instituições. Informação \& Sociedade: Estudos, v. 22, n. 1, p. 6778, 2012. Disponível em:

http://www.ies.ufpb.br/ojs2/index.php/ies/article/view/9747. Acesso em: 14 jan. 2016.

MOREIRO GONZALEZ, J. A.; VERGUEIRO, W. de C. S. Ofertas de trabalho na Web para os profissionais brasileiros da informação-documentação: análise das competências e habilidades exigidas pelas empresas e instituições.

Perspectivas em Ciências da Informação, Belo Horizonte, v. 17, n. 1, p. 231250, jan./mar. 2012. Disponível em:

http://www.scielo.br/pdf/pci/v17n1/a13v17n1.pdf. Acesso em: 14 mar. 2016.

NIELSEN, J. M. The Blended Business Librarian: Technology Skills in Academic Business Librarian Job Advertisements. Journal of Business \& Finance Librarianship, v.18, n.2, p.119-128, 2013.

PRENSKY, M. Digital Natives Digital Immigrants. In: PRENSKY, M. On the Horizon. MCB University Press, v. 9, n. 5, out. 2001. Disponível em: http://www.marcprensky.com/writing/Prensky\%20\%20Digital\%20Natives,\%20Digital\%20Immigrants\%20-\%20Part1.pdf. Acesso em: 13 mar. 2016.

PORTAL Catho Online Ltda. Buscar vagas. Barueri, São Paulo, 2012-2014. Disponível em: www.catho.com.br. Acesso em: 29 dez. 2015.

TEJADA-ARTIGAS, C.; CHACÓN JARÉN, S.; MOREIRO-GONZÁLEZ, J. A. Mercado de trabajo en información y documentación y crisis económica en España: una aproximación a partir de las ofertas publicadas en IweTel entre 2008 y 2013. BiD: textos universitaris de biblioteconomia i documentació, n. 32, jun. 2014. Disponível em: http://bid.ub.edu/es/32/tejada2.htm. Acesso em: 21 mar. 2016. 
VALENTIM, M. L. P. Criatividade e Inovação na Atuação Profissional. CRB-8. Digital, São Paulo, v. 1, n. 1, p. 3-9, jul. 2008. Disponível em:

http://revista.crb8.org.br/index.php/crb8digital/article/viewFile/36/37. Acesso em: 14 mar. 2016.

\title{
OFFER OF EMPLOYMENT: SKILLS REQUIRED FOR ARCHIVISTS IN COMPANIES AT THE BRAZIL
}

\begin{abstract}
Introduction: The present study analyzes the skills required of Brazilian archivists and documentalists in work offers available for information management in companies, industries and organizations. Objective: to map the skills required of archivists in the Brazilian labor market. The mining of the terms, in the period 2012-2014, in advertisements available on the Portal Catho (www.catho.com.br). The taxonomic structure was used in TEMATRES - Thesaurus management software. Methodology: applied the qualitative and quantitative exploratory method in this study. Results: The dice demonstrate a relevant incidence of skills, with average request of three specific skills in each of the 3,291 ads analyzed, which are: instrumental skills, computational skills and personal skill. Conclusions: the labor market studied requires professional skills specific to archival candidates and documentalists, such skills are decisive for the selection of these professionals. The skills identified reveal a new social and labor context in which archivists and documentalists perform their roles according to the qualification demanded by the market.
\end{abstract}

Descriptors: Business archivists. Skills - Archivist. Work offers. Portal Catho - Brazil. Work market. Taxonomy. TEMATRES.

\section{OFERTA DE EMPLEO: HABILIDADES NECESARIAS PARA ARCHIVISTAS EN EMPRESAS EN BRASIL}

\begin{abstract}
RESUMEN
Introducción: el presente estudio analiza las habilidades requeridas a los archivistas y documentalistas brasileños en ofertas de empleo disponibles para gestión de la información en empresas, industrias y organismos. Objectivo: mapear las habilidades requeridas a los archivistas en el mercado de trabajo brasileño. La minería de los términos, en el período 2012-2014, en anuncios disponibles en el Portal Catho (www.catho.com.br). Se utilizó la estructura taxonómica en el TEMATRES - software para gestión de tesauros. Metodología: aplicó en este estudio el método exploratorio cualitativo y cuantitativo. Resultados: los datos muestran una incidencia relevante de las habilidades, con la media de tres habilidades específicas en cada uno de los 3.291 anuncios analizados, que son: aptitudes instrumentales, habilidades computacionales y habilidades personales. Conclusiones: el mercado de trabajo estudiado requiere como perfil profesional habilidades específicas a los candidatos archivistas y documentalistas, tales habilidades son decisivas para la selección de los profesionales. Las habilidades identificadas revelan un nuevo contexto laboral y social, en el cual, archivistas y documentalistas desarrollan sus funciones de acuerdo con la calificación exigida por el
\end{abstract}

Inf. Inf., Londrina, v. 24, n. 1, p. 424 - 441, jan./abr. 2019. 
mercado.

Descriptores: Archivistas empresariales. Habilidades - Archivista. Ofertas de empleo. Portal Catho - Brasil. Mercado de trabajo. Taxonomía. TEMATRES. 